\title{
Stability of the Glycerol Facilitator in Detergent Solutions ${ }^{\dagger}$
}

\author{
Jamie J. Galka, Simon J. Baturin, Darren M. Manley, Angela J. Kehler, and Joe D. O'Neil* \\ Department of Chemistry, University of Manitoba, Winnipeg, Manitoba, R3T 2N2 Canada \\ Received October 23, 2007; Revised Manuscript Received January 21, 2008
}

\begin{abstract}
Understanding membrane protein folding and stability is required for a molecular explanation of function and for the development of interventions in membrane protein folding diseases. Stable aqueous detergent solutions of the Escherichia coli glycerol facilitator in its native oligomeric state have been difficult to prepare as the protein readily unfolds and forms nonspecific aggregates. Here, we report a study of the structure and stability of the glycerol facilitator in several detergent solutions by Blue Native and sodium dodecyl sulfate (SDS) - polyacrylamide gel electrophoresis (PAGE), circular dichroism (CD), and fluorescence. Protein tetramers were prepared in neutral dodecyl maltoside (DDM) and in zwitterionic lysomyristoylphosphatidylcholine (LMPC) detergent solutions that are stable during SDS-PAGE. Thermal unfolding experiments show that the protein is more stable in LMPC than in DDM. Tertiary structure unfolds before quaternary and some secondary structure in LMPC, whereas unfolding is more cooperative in DDM. The high stability of the protein in DDM is evident from the unfolding half-life of 8 days in 8 $\mathrm{M}$ urea, suggesting that hydrophobic interactions contribute to the stability. The protein unfolds readily in LMPC below $\mathrm{pH}$ 6, whereas the tetramer remains intact at $\mathrm{pH} 4$ in DDM. At $\mathrm{pH} 4$ in DDM, the protein is more sensitive than at neutral $\mathrm{pH}$ to unfolding by SDS and the effect is reversible. At $\mathrm{pH} 3$ in DDM, the tetramer unfolds, losing its tertiary structure but retaining native helical structure which melts at significantly lower temperatures than in the native tetramer. The glycerol facilitator prepared in SDS is mainly monomeric and has $10 \%$ less $\alpha$-helix than the native protein. CD suggests that it forms a condensed structure with non-native tertiary contacts highly similar to the state observed in LMPC at low $\mathrm{pH}$. The implications of the results for in vitro and in vivo folding of the protein are discussed.
\end{abstract}

Membrane proteins (MP) ${ }^{1}$ are important elements of a wide variety of cellular processes, including the transport of molecules and ions, the reception and transduction of cell signals, and the transmission of light, electrical, and chemical energy. Despite their importance, much less is known about the structures, dynamics, and folding of membrane proteins than about their water-soluble counterparts. Some of the impediments to membrane protein analysis are low levels of cellular expression sometimes coupled with cytotoxicity upon overexpression, poor solubility in water, and a tendency to aggregate irreversibly $(1-4)$. In addition, some membrane proteins appear to resist crystallization because of intrinsic conformational flexibility that is integral to their function (2). For example, lactose permease would not crystallize until

${ }^{\dagger}$ The financial assistance of the Natural Sciences and Engineering Research Council of Canada and the University of Manitoba is gratefully acknowledged.

* To whom correspondence should be addressed. E-mail: joneil@ cc.umanitoba.ca. Telephone: (204) 474-6697. Fax: (204) 474-7608.

${ }^{1}$ Abbreviations: AIDA, adhesin involved in diffusion adherence; AQP, aquaporin; Bis-Tris, bis(2-hydroxyethyl)aminotris(hydroxymethyl)methane; BN, Blue Native; CD, circular dichroism; DTT, dithiothreitol; DDM, dodecyl $\beta$-D-maltoside; EDTA, ethylenediaminetetraacetic acid; GF, glycerol facilitator; LMPC, lysomyristoylphosphatidylcholine; MALDI, matrix-assisted laser desorption ionization; MP, membrane proteins; $M_{\mathrm{r}}$, relative mass; MRE, mean residue ellipticity; NMR, nuclear magnetic resonance; NTA, nitrilotriacetic acid; OG, octyl $\beta$-D-glucopyranoside; PAGE, polyacrylamide gel electrophoresis; pI, isoelectric point; SDS, sodium dodecyl sulfate; TM, transmembrane; TOFMS, time-of-flight mass spectrometry; Tris, tris(hydroxymethyl)aminomethane; UV, ultraviolet. mutants were found that reduced its intrinsic flexibility (5), and the $\mathrm{KvAP} \mathrm{K}^{+}$channel required complexation with monoclonal Fab fragments for crystallization (6). The flexibility and tendency to aggregate suggest a low thermodynamic stability; however, a survey of diffraction data for MP indicates that they are at least as tightly packed as watersoluble proteins $(7,8)$. Direct measurements of membrane protein thermodynamic stability are problematic because of irreversible aggregation of the unfolded proteins $(9,10)$. Reversible chemical denaturation of a $\beta$-barrel protein has been reported (11), but in general, helical bundle proteins have proven to be more difficult to refold. It has recently been pointed out that helical bundle membrane proteins retain much of their secondary structure in sodium dodecyl sulfate (SDS), limiting its value as a chemical denaturant (12).

Because of the tendency of MP to aggregate, prokaryotic and eukaryotic cells have evolved a complex machinery to chaperone their folding and insertion into membranes. The current view of helical bundle protein folding is that transmembrane (TM) helix formation occurs in the aqueous channel of the translocon and that most or all of the tertiary structure formation occurs following partitioning of the protein into the lipid bilayer $(9,12-15)$. While the structure of the archaeal Sec Y translocon (16) has shed light on the process of membrane insertion, features of the sequencespecific code for transmembrane helices suggest that direct interactions with the membrane lipid are critical for insertion by the translocon (17). That the lipid bilayer plays a more 
than passive structural role in directing MP folding is also suggested by the fact that phosphatidylethanolamine is essential for the correct folding of lactose permease (18) and by molecular dynamics simulations (19). A two-stage working model of in vitro helix bundle MP folding was first proposed by Popot and Engelman (20-22) and then was expanded by White and Wimley (23). The broad outlines of the in vitro and in vivo models are surprisingly alike. In vitro folding begins with the partitioning of the protein to the membrane interface and is followed by $\alpha$-helix formation, insertion of helices across the bilayer, and finally condensation to the native helix bundle (23). Quaternary structure might form through the association of monomers that have native tertiary structure or by the association of molten globule-like monomers that achieve their tertiary structure only in the oligomer (22).

The glycerol facilitator (GF) integral membrane protein from Escherichia coli is a member of the aquaporin family of proteins (24) and is an attractive model for studying membrane protein folding (25-27). GF permits the passage of glycerol and other low-molecular weight polyols, but not sugars, across the inner membrane of the bacterium (28-32). $\mathrm{X}$-ray diffraction reveals a tetrameric, six-transmembrane $\alpha$-helical protein that contains two additional half-membrane helices that line the glycerol pore (26). Although in vivo protein oligomer structure is often retained in crystals, determination of the structure of native oligomers is not straightforward even for water-soluble proteins $(33,34)$. The paucity of membrane protein structures has precluded systematic investigations of their quaternary structures, but it is worth noting that bacteriorhodopsin crystallizes both as a monomer $(35)$ and as a trimer $(36,37)$. The oligomeric state of the GF has been the subject of numerous investigations by sedimentation on sucrose density gradients $(38-40)$, cryo-electron microscopy $(41,42)$, freeze-fracture electron microscopy $(43,44)$, chemical cross-linking (27), and sodium dodecyl sulfate-polyacrylamide gel electrophoresis (SDSPAGE) $(27,38-44)$. Most investigators have found the protein to exist as a monomer in SDS and as a mixture of oligomers in octyl glucoside, $N$-lauryl sarcosine, Triton X-100, and yeast, E. coli, and Xenopus membranes. This contrasts with the behavior of several of the homologous aquaporins that retain tetrameric structure even under the denaturing conditions of SDS-PAGE, including AQP0 $(45,46)$, AQP1 (47, 48), AQP2 (49), AQP4 (48), AQPcic (50), and AQP-Z (51). The generally accepted conclusion has been that GF is a weakly associating protein both in membranes and upon dissolution with detergents. However, it should be noted that a mixture of GF oligomers can also be prepared by adding urea to detergent-solubilized protein (52) and by sample aging, suggesting that the observed oligomers represent nonspecific associations of denatured protein induced by the extraction and/or measurement conditions. Finding conditions under which membrane proteins retain their native oligomeric state is important for dynamics studies, for understanding membrane protein folding, and in functional studies, as the oligomeric state of many membrane proteins is an important aspect of their regulation (53). Furthermore, although the seven-TM bacteriorhodopsin and several $\beta$-barrel porins have been thoroughly characterized, there have been no studies of the folding and stability of members of the aquaporin family (12).
We previously described the overexpression and characterization of the secondary structure of the glycerol facilitator in several detergents (27). Here, we describe for the first time two detergent preparations of the glycerol facilitator that show the same quaternary structure and stability as many of the aquaporins on SDS-PAGE. The native tetramer and low-pH states are characterized by denaturing and Blue Native (BN) polyacrylamide gel electrophoresis (PAGE), farand near-ultraviolet circular dichroism (CD) spectropolarimetry, fluorescence spectroscopy, and sensitivity to $\mathrm{pH}$, heat, urea, and SDS.

\section{MATERIALS}

Dodecyl $\beta$-D-maltoside was purchased from Anatrace (Maumee, OH) or Sigma (St. Louis, MO). Sodium dodecyl sulfate, octyl $\beta$-D-glucopyranoside, Coomassie Brilliant Blue $\mathrm{R}-250, \beta$-mercaptoethanol, and urea were obtained from Sigma. 1-Myristoyl-2-hydroxy-sn-glycero-3-phosphocholine (LMPC) was from Avanti Polar Lipids (Alabaster, AL). BisTris, Coomassie Brilliant Blue G-250, glycerol, and Tris were from Fisher Scientific (Fairlawn, NJ). Bromophenol blue was from BDH Inc. (Toronto, ON). Dithiothreitol was from Aldrich Chemical Co. (Milwaukee, WI), and imidazole was from Fluka (Buchs, Switzerland). Nickel-nitrilotriacetic acid (NTA) resin was from Qiagen (Toronto, ON). SDS-PAGE molecular weight markers were from Fermentas Life Sciences (Burlington, ON), and bovine serum albumin, the molecular weight standard for BN-PAGE, was from Sigma. All other materials were of the highest purity commercially available.

\section{METHODS}

Glycerol Facilitator Expression and Purification. The E. coli glycerol facilitator was expressed in BL21(DE3)pLysS cells (54) or C43(DE3) cells (55) from a pET28b (+) plasmid (Novagen) encoding an $\mathrm{N}$-terminal His 6 purification tag and T7 epitope, as described previously $(27,30,52)$. The $M_{\mathrm{r}}$ of the GF, including the N-terminal fusion tags, is $33505 \mathrm{Da}$ and was confirmed by mass spectrometry (27); its calculated $\mathrm{pI}$ is 7.2 (MacVector, Oxford Molecular). For the purposes of purification of the glycerol facilitator, E. coli cells were mechanically sheared by brief sonication on ice, unbroken cells were removed by centrifugation, and membranes were prepared by ultracentrifugation at $100000 \mathrm{~g}$ for $60 \mathrm{~min}$, at 4 ${ }^{\circ} \mathrm{C}$, in a Beckman sw28 rotor and either a Beckman L8 70 $\mathrm{M}$ or Beckman-Coulter LE 80k centrifuge (56). The membranes were solubilized in $25 \mathrm{mM}$ sodium phosphate buffer (pH 7.6) containing $200 \mathrm{mM} \mathrm{NaCl}, 2 \mathrm{mM} \beta$-mercaptoethanol, and dodecyl $\beta$-D-maltoside (30 mM), octyl $\beta$-D-glucopyranoside $(50 \mathrm{mM})$, sodium dodecyl sulfate $(150 \mathrm{mM})$, or lysomyristoylphosphatidylcholine $(20 \mathrm{mM})$, and the protein was purified using immobilized metal chelate chromatography. Protein purification was conducted by washing the resin with $15 \mathrm{~mL}$ of $25 \mathrm{mM}$ sodium phosphate buffer (pH 7.5) containing $200 \mathrm{mM} \mathrm{NaCl}, 30 \mathrm{mM}$ imidazole, and detergent ( $3 \mathrm{mM}$ DDM, $25 \mathrm{mM}$ OG, $2 \mathrm{mM}$ LMPC, or 150 $\mathrm{mM}$ SDS). The resin was next washed with the same buffer containing $50 \mathrm{mM}$ imidazole until the $A_{280}$ was below 0.01 . GF was eluted from the $\mathrm{Ni}^{2+}$-NTA column using the same buffer containing $250 \mathrm{mM}$ imidazole. In the case of SDSsolubilized protein, the resin was washed with $5 \mathrm{mM}$ 
imidazole and the protein eluted using $50 \mathrm{mM}$ imidazole or elution was conducted by lowering the $\mathrm{pH}$ as described previously (27). For the far-UV CD experiments, GF samples were dialyzed twice against buffer containing no imidazole. Adjustment of the $\mathrm{pH}$ was done by adding glacial acetic acid (up to $50 \mathrm{mM}$ ) followed by concentrated $\mathrm{HCl}$, if necessary. Protein purity was analyzed by SDS-PAGE (57) and MALDI mass spectrometry (27).

Electrophoresis. For the SDS denaturing gels, protein was incubated in $50 \mathrm{mM}$ Tris- $\mathrm{HCl}$ (pH 6.8), $2 \%$ SDS, $0.1 \%$ bromophenol blue, $10 \%$ glycerol, and $1 \%$ (v/v) $\beta$-mercaptoethanol for $10 \mathrm{~min}$ at $25^{\circ} \mathrm{C}$, prior to being loaded on the gel. Separation was achieved by SDS-PAGE in Laemmli discontinuous gels (57) composed of a $4 \%$ polyacrylamide stacking gel and a 10\% resolving gel. After electrophoresis, proteins were visualized by staining with Coomassie Brilliant Blue R250.

For the Blue Native gels (58), protein was incubated in 80 mM Bis-Tris- $\mathrm{HCl}$ (pH 7.0), 400 mM 6-aminocaproic acid, and Coomassie Brilliant Blue G-250 (1/100 of detergent) for $10 \mathrm{~min}$ at $25{ }^{\circ} \mathrm{C}$ prior to being loaded on the gel. BNPAGE was carried out using step gradient gels with a 4 to $10 \%$ polyacrylamide step gradient at $5{ }^{\circ} \mathrm{C}$. Electrophoresis was started at $50 \mathrm{~V}$ and continued until all the protein entered the gel, after which the voltage was increased to $200 \mathrm{~V}$ for 3-4 h. Coomassie-stained polyacrylamide gel bands were quantified with Un-Scan-It digitizing software from Silk Scientific, Inc.

Circular Dichroism and Fluorescence. CD and fluorescence spectra were acquired with a Jasco 810 spectropolarimeter/fluorometer or a Jasco J500 A spectropolarimeter. The sample temperature was controlled by a Julabo F25 circulating water bath or with a built-in Peltier device. Briefly, for acquisition of far-UV CD spectra, protein solutions were placed in a quartz cuvette with a $0.1 \mathrm{~cm}$ path length and spectra were collected at $20 \mathrm{~nm} / \mathrm{min}$ between 250 and $185 \mathrm{~nm}$ with a response time of $8 \mathrm{~s}$ and a data pitch of $0.1 \mathrm{~nm}$. For near-UV spectra, the samples were placed in a quartz cuvette with a $1.0 \mathrm{~cm}$ path length and spectra were collected at $20 \mathrm{~nm} / \mathrm{min}$ or $5 \mathrm{~nm} / \mathrm{min}$ between 340 and 250 $\mathrm{nm}$ with a response time of $8 \mathrm{~s}$ or $30 \mathrm{~s}$ and a data pitch of $0.1 \mathrm{~nm}$. Baselines were collected in the same fashion on buffer solutions, and spectra were baseline corrected. Protein concentrations were determined using the calculated molar absorptivity of $38305 \mathrm{M}^{-1} \mathrm{~cm}^{-1}$ and are indicated in the figure legends. Note that due to the weak molar absorptivity of the aromatic amino acids, the protein concentrations required for near-UV CD measurements are on the order of 10 -fold greater than those required for far-UV measurements. The CD intensity and wavelength of the spectropolarimeter were calibrated using solutions of $d$-10-camphorsulfonic acid (59). Mean residue ellipticities $\left([\theta] \times 10^{-3} \mathrm{deg} \mathrm{cm}^{2} \mathrm{dmol}^{-1}\right)$ were calculated using the equation $[\theta]_{\mathrm{M}}=M \theta /(10)(l)(c)(n)$, where $M$ is $33505 \mathrm{~g} / \mathrm{mol}, \theta$ is the measured ellipticity in millidegrees, $l$ is the cell path length, $c$ is the protein concentration in grams per liter, and $n=316$ residues. Deconvolution of the CD spectra into pure component spectra was performed using the algorithm CDSSTR (60) accessed through Dichroweb (61). For calculations of helix content, we have assumed that none of the 35 amino acids in the $\mathrm{His}_{6}$-T7 tag are helical. Fluorescence spectra were collected in a $1 \mathrm{~cm}^{2}$ rectangular quartz cell with a $0.5 \mathrm{~s}$ response time, a data pitch of $1 \mathrm{~nm}$, a scanning speed of $100 \mathrm{~nm} / \mathrm{min}$, and excitation and emission bandwidths of 8 and $10 \mathrm{~nm}$, respectively. Thermal denaturation of membrane proteins is usually an irreversible process because the unfolded proteins aggregate and is therefore carried out for comparative purposes only. The thermal denaturation rate was $60{ }^{\circ} \mathrm{C} / \mathrm{h}$ so that experiments using different probes and protein in different detergents would be self-consistent and comparable to experiments in the literature (62).

Curve Fitting. Near- and far-UV CD temperature titrations were fitted to the following equation $(62,63)$

$$
Y_{\text {obs }}=\frac{Y_{\mathrm{f}}+m_{\mathrm{f}} T+\left(Y_{\mathrm{u}}+m_{\mathrm{u}} T\right) \mathrm{e}^{\left(-\Delta H_{\mathrm{vH}} / R\right)\left(1 / T-1 / T_{\mathrm{m}}\right)}}{1+\mathrm{e}^{\left(-\Delta H_{\mathrm{vH}} / R\right)\left(1 / T-1 / T_{\mathrm{m}}\right)}}
$$

where $Y_{\mathrm{obs}}$ is the observed ellipticity, $Y_{\mathrm{f}}$ and $Y_{\mathrm{u}}$ are the ellipticities of the low- and high-temperature forms of the protein, respectively, $m_{\mathrm{f}}$ and $m_{\mathrm{u}}$ are the slopes of the curves at low and high temperatures, respectively, $R$ is the gas constant, $T$ is the temperature, and $\Delta H_{\mathrm{vH}}$ is the van't Hoff enthalpy change of unfolding (62). The equation fits the thermal dependence of the ellipticity to a two-state unfolding transition yielding a value for $T_{\mathrm{m}}$, the midpoint of the transition where the concentrations of folded and unfolded protein are equal. As the unfolding reactions are, in most cases, irreversible, the fits were used only to extract $T_{\mathrm{m}}$ values as quantitative indicators of the thermal stability of the protein $(9,10)$. The cooperativity of the transitions was quantified by calculating the range of temperatures $(\Delta T)$ over which $80 \%$ of the unfolding occurs and which corresponds to a $K_{\text {eq }}$ range of $1 / 9-9$. The urea unfolding rate constant was obtained by fitting changes in near-UV CD ellipticity at $268 \mathrm{~nm}$ to the following equation:

$$
\left|Y_{\text {obs }}\right|=A \mathrm{e}^{-k t}
$$

All the fits were done using the nonlinear least-squares fitting program in Mathematica, version 5.1 (64).

\section{RESULTS}

Glycerol Facilitator in DDM and LMPC at Neutral pH. In all previous reports of detergent solutions of the glycerol facilitator, the protein appeared predominantly monomeric by several assays, although SDS-PAGE sometimes showed varying amounts of dimer, trimer, tetramer, and highermolecular weight species $(27,38-44)$. These observations have led to the suggestion that, in contrast to the aquaporins, the glycerol facilitators exist as monomers or weakly associating tetramers in membranes. In contrast, the results in Figure 1 show that recombinant GF, prepared by elution with imidazole from an immobilized $\mathrm{Ni}^{2+}$ resin at $\mathrm{pH}$ 7.0, exists predominantly as a tetramer in both DDM and LMPC according to SDS-PAGE (Figure 1A, lane 1 for DDM, and Figure 1C, lane 4 for LMPC). Because a two- $\mathrm{Mg}^{2+}$ ion coordination site was identified at the 4-fold symmetry axis of the GF tetramer crystal structure (26), we also investigated the separate effects of $100 \mathrm{mM}$ EDTA, $50 \mathrm{mM} \mathrm{Mg}^{2+}$, and $50 \mathrm{mM} \mathrm{Ca}^{2+}$ on the tetramer. SDS-PAGE gave results identical to those shown in Figure 1A, ruling out the possibility that the tetramer is held together by metal chelation and further eliminating the possibility that the tetramer is an artifact of metal ion-mediated $\mathrm{His}_{6}$ tag 
A

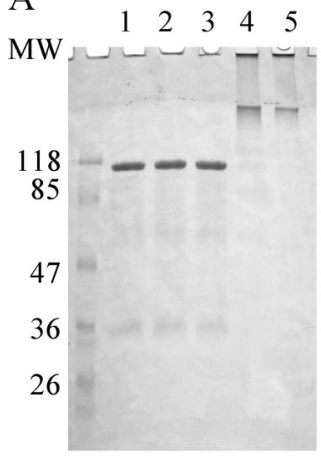

$\mathrm{C}$

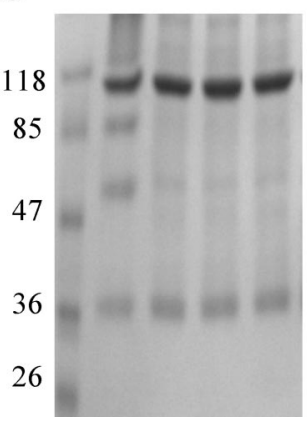

B

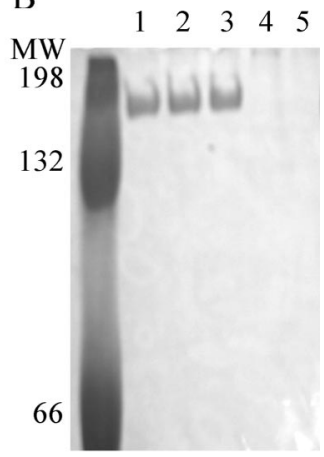

$\mathrm{D}$

$\begin{array}{llll}1 & 2 & 3 & 4\end{array}$

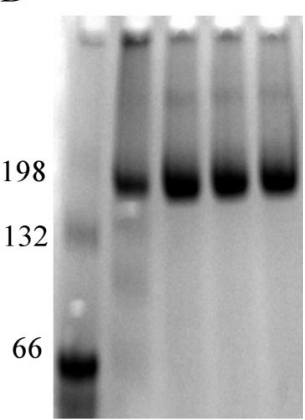

FIGURE 1: Thermal unfolding of GF quaternary structure by (A) SDS-PAGE and (B) BN-PAGE for DDM-solubilized protein (lane $1,20{ }^{\circ} \mathrm{C}$; lane $2,40{ }^{\circ} \mathrm{C}$; lane $3,60{ }^{\circ} \mathrm{C}$; lane $4,80{ }^{\circ} \mathrm{C}$; lane 5,95 ${ }^{\circ} \mathrm{C}$ ) and (C) SDS-PAGE and (D) BN-PAGE for LMPC-solubilized protein (lane $1,95^{\circ} \mathrm{C}$; lane $2,80^{\circ} \mathrm{C}$; lane $3,60^{\circ} \mathrm{C}$; lane $4,40^{\circ} \mathrm{C}$; lane $5,20^{\circ} \mathrm{C}$ ). BN-PAGE MW standard: BSA dissolved in $3 \mathrm{mM}$ DDM. The $M_{\mathrm{r}}$ of BSA is $66430 \mathrm{Da}$. GF tetramers electrophorese faster on SDS-PAGE than an unfolded water-soluble protein of the same size presumably because a folded membrane protein binds more SDS per residue than the unfolded water-soluble proteins.

association. The observations of tetramer via SDS-PAGE are also confirmed by electrophoresis of the same preparations on gentler Blue Native polyacrylamide gels (Figure 1B, lane 1 for DDM, and Figure 1D, lane 4 for LMPC). Since monomer, dimer, and trimer are virtually undetectable on the BN gels whereas the SDS gels reveal small amounts of the lower- $M_{\mathrm{r}}$ species, this suggests that the SDS present during SDS-PAGE causes slight dissociation of the tetramer. Interestingly, a small amount of an apparent octameric protein is sometimes observed in protein prepared both in DDM and in LMPC (see Figure 1D, lane 4).

$\mathrm{CD}$ and fluorescence spectroscopy were used to characterize the secondary and tertiary structures of the protein prepared at neutral $\mathrm{pH}$ in DDM and in LMPC detergent solutions. The far-UV CD spectra of GF dissolved in DDM at various temperatures, shown in Figure 2A, display the characteristics of a predominantly $\alpha$-helical protein with negative bands at 219-222 and 209-211 nm, a positive band at $191-192 \mathrm{~nm}$, and a crossover point at $200-201 \mathrm{~nm}$. The ideal $\alpha$-helical values are 222, 208, 190-195, and $205 \mathrm{~nm}$, respectively (65). Deconvolution of the CD spectrum measured at $20{ }^{\circ} \mathrm{C}$ using the CDSSTR algorithm (60) yields 53\% $\alpha$-helix, $17 \% \beta$-strand, $15 \%$ turns, and $15 \%$ unordered structure. Nearly identical values are obtained for GF dissolved in LMPC (Figure S1), where spectral deconvolution yields $53 \% \alpha$-helix, $10 \% \beta$-strand, $15 \%$ turns, and $22 \%$ unordered structure. On the assumption that the 35-residue His $_{6}$-T7 tag is disordered, the deconvolutions indicate that $60 \%$ of the GF residues are helical in these detergents, a

result that is in close agreement with the secondary structure observed by X-ray diffraction where $61 \%$ of the residues are $\alpha$-helical, $3 \%$ are 310 -helical, and the balance are in turns or irregular structure (26).

Near-UV CD spectra of the glycerol facilitator tetramer solubilized in DDM at neutral $\mathrm{pH}$ and various temperatures are shown in Figure 2B. Near-UV circular dichroism is usually interpreted as indicating the presence of tertiary structure in proteins as only aromatic residues held rigidly in an asymmetric environment will display near-UV CD bands (66). The spectrum of GF in DDM shows strong, welldefined, negative bands between 255 and $290 \mathrm{~nm}$ and a positive band centered at $295 \mathrm{~nm}$. Phenylalanine would be expected to contribute the least to the CD spectrum due to its high structural symmetry and the low sensitivity of its transitions to changes in solvent polarizability (67). Nevertheless, because of their relatively high abundance, the 21 phenylalanine residues in GF are the likely origin of the band $\left({ }^{1} \mathrm{~L}_{\mathrm{b}}\right)$ at approximately $258 \mathrm{~nm}$ (Figure 2B). The small shoulder at $295 \mathrm{~nm}$ is most likely attributable to the ${ }^{1} \mathrm{~L}_{\mathrm{b}}$ transitions of the seven tyrosine residues (65). Tryptophan residues usually dominate the near-UV $\mathrm{CD}$ spectra of proteins because of their large molar absorptivity, and the bands between 265 and $290 \mathrm{~nm}$ are attributable to the five tryptophan residues; the $\operatorname{Trp}{ }^{1} \mathrm{~L}_{\mathrm{a}}$ band is usually near 275 $\mathrm{nm}$, and the ${ }^{1} \mathrm{~L}_{\mathrm{b}}$ doublet usually falls between 280 and 290 $\mathrm{nm}$ (66). The near-UV CD spectrum of the protein dissolved in LMPC (Figure 2E) is nearly identical to that observed in DDM except that the weak band at $290 \mathrm{~nm}$ in DDM is positive and the positive band at $295 \mathrm{~nm}$ intensifies when the protein is dissolved in LMPC. The observation of welldefined $\mathrm{CD}$ absorbance bands suggests that the aromatic amino acids are fixed firmly in the structure in asymmetric environments and is a strong indication of a stable tertiary fold in both detergents.

Fluorescence spectra of GF dissolved in DDM are virtually identical to those measured in LMPC (see panels A and B of Figure S2). They both exhibit a peak at $329 \mathrm{~nm}$ and no evidence of Tyr emission at $303 \mathrm{~nm}$. In folded globular proteins, tyrosine emission is often highly quenched by radiationless energy transfer to tryptophan as well as by interactions with other protein groups (68). The emission maximum for tryptophan in proteins is sensitive to both the polarity and the dynamics of the environment surrounding the side chain and is blue-shifted from $350 \mathrm{~nm}$ in environments of low polarity such as the hydrophobic interior of a protein or in a detergent micelle. Burstein and colleagues have classified Trp fluorescence in proteins into five classes depending on the polarity and dynamics of the Trp environments (69). According to their scheme, the dominant fluorescence at $329 \mathrm{~nm}$ in GF corresponds closely to a class of Trp side chains that are in a relatively nonpolar environment and $\mathrm{H}$-bonded in a 2:1 exciplex that fluoresces at 331 $\mathrm{nm}$ (69). Inspection of the three-dimensional structure of GF (26) indicates that Trp-42 is well buried in the intermonomer interface and Trp-219 is buried but close to the surface of the protein. Two Trp side chains (76 and 215) project from the lateral surfaces of the protein and likely contact detergent but could also interact with water. In the crystal structure, Trp-48 forms part of the lining of the glycerol channel (26). However, it too is in a hydrophobic environment contacting Leu, Ile, Phe, and Val side chains and exposing only one 

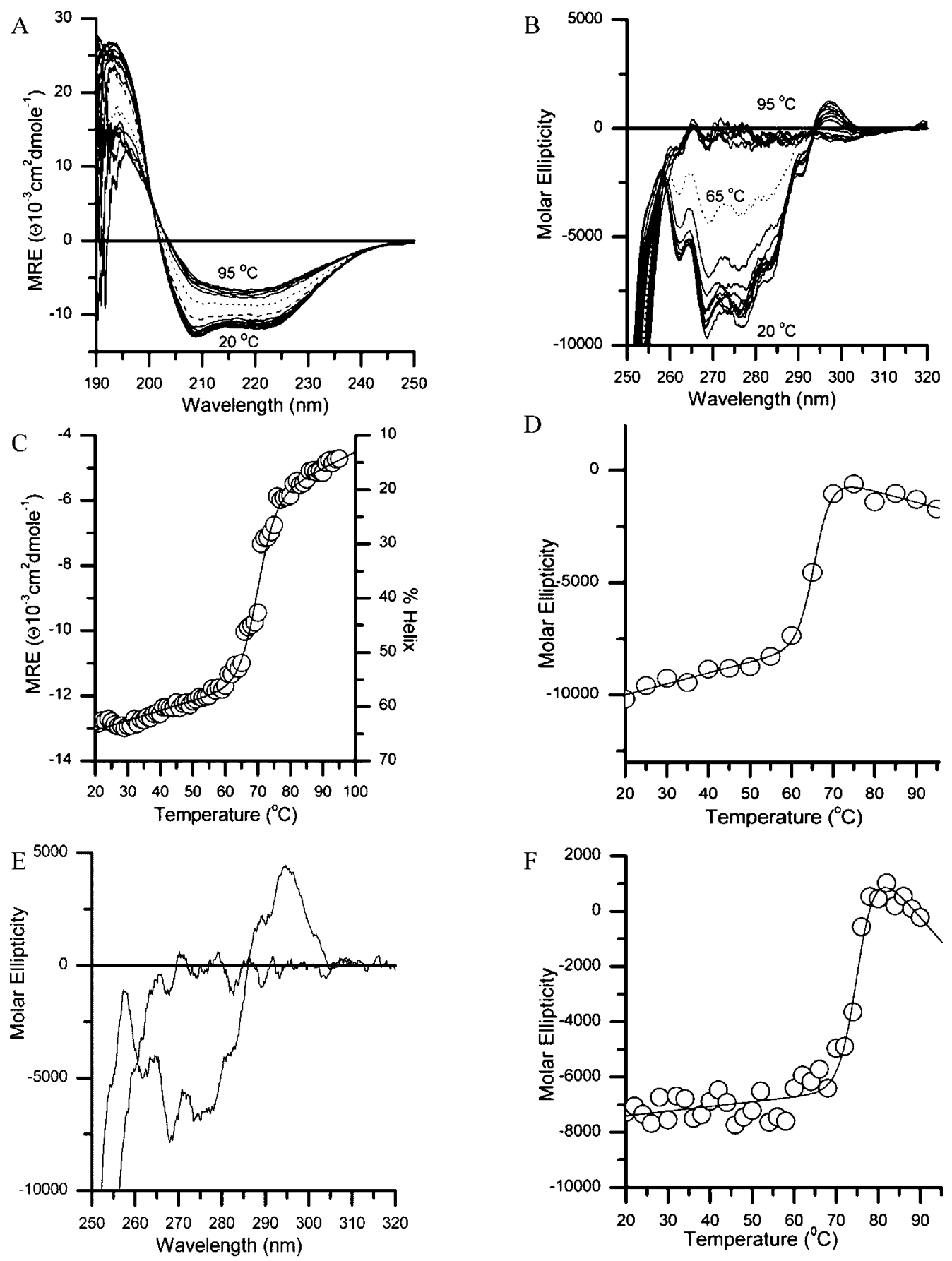

FIGURE 2: Thermal unfolding of secondary and tertiary structure of DDM- and LMPC-solubilized GF. (A) Far-UV CD spectra of $3.3 \mu$ M GF in DDM between 20 and $95^{\circ} \mathrm{C}$ in $5{ }^{\circ} \mathrm{C}$ intervals. (B) Near-UV CD spectra of $69 \mu \mathrm{M}$ GF in DDM between 20 and $95{ }^{\circ} \mathrm{C}$ in $5{ }^{\circ} \mathrm{C}$ intervals. (C) MRE at $209 \mathrm{~nm}$ from panel A as a function of temperature fit to a two-state unfolding transition as described in Methods. The fractional helicity was determined by deconvolution as described in Methods, and the results agree with the scale on the right side of panel $\mathrm{C}$ within $\pm 5 \%$. (D) Molar ellipticity at $268 \mathrm{~nm}$ from panel B as a function of temperature fit to a two-state unfolding transition. (E) Near-UV CD spectrum of $25 \mu \mathrm{M}$ GF in LMPC at $20^{\circ} \mathrm{C}$ and $95{ }^{\circ} \mathrm{C}$. (F) Molar ellipticity at $268 \mathrm{~nm}$ from panel E as a function of temperature fit to a two-state unfolding transition.

edge of the ring to channel water. In summary, the fluorescence results are compatible with the observations of native secondary, tertiary, and quaternary structure described above and with the three-dimensional structure determined by X-ray diffraction (26).

Effects of Heat and Urea. To measure the stability of GF prepared in DDM and LMPC at $\mathrm{pH} 7$, the effects of temperature and urea were examined. The thermal stabilities of the quaternary structure of the protein dissolved in DDM and LMPC were measured by SDS-PAGE (Figure 1A,C) and BN-PAGE (Figure 1B,D), and in each case, the protein was heated at a rate of $1{ }^{\circ} \mathrm{C} / \mathrm{min}$. SDS-PAGE indicates that the tetramer in DDM is stable up to $60{ }^{\circ} \mathrm{C}$. Above $60{ }^{\circ} \mathrm{C}$, the protein unfolds, forming at least two high-molecular weight complexes; one aggregate enters both the stacking and running gels, and the other just enters the stacking gel (Figure 1A). The aggregation also eliminates the traces of monomer, dimer, and trimer that were present initially. Quantification of the gels indicates that at $60{ }^{\circ} \mathrm{C}$ only $9 \%$ of the tetramer has unfolded whereas at $80{ }^{\circ} \mathrm{C} 95 \%$ has unfolded. The results of BN-PAGE of the protein heated in DDM are shown in Figure 1B. The unfolding and aggrega- 
tion of $\mathrm{GF}$ above $60{ }^{\circ} \mathrm{C}$ are evidenced only by the disappearance of the tetrameric protein from the gels, suggesting that the high- $M_{\mathrm{r}}$ oligomers are too large to enter the cross-linked polyacrylamide. This further suggests that the oligomers observed on the SDS gel in Figure 1A underestimate the actual oligomer size formed at high temperatures in DDM because of the ability of SDS to dissociate them. The thermal stability of the glycerol facilitator tetramer was also measured in LMPC. Both SDS-PAGE (Figure 1C) and BN-PAGE (Figure 1D) indicate that the GF tetramer is more thermally stable dissolved in LMPC than in DDM because $60 \%$ of the tetramer is still intact even at $80{ }^{\circ} \mathrm{C}$.

The thermal unfolding of the protein's secondary structure in DDM was followed by far-UV CD spectropolarimetry, and the spectra are shown in Figure 2A. The isodichroic point at $201 \mathrm{~nm}$ suggests that a two-state transition is occurring. Plots of the temperature dependence of the ellipticity at 209 $\mathrm{nm}$ fit to a two-state unfolding transition are shown in Figure 2C. Although the unfolding transitions are not reversible, the transition midpoints can be used to quantify the thermal stability of the protein (9). The spectra indicate that in DDM the protein secondary structure is stable up to $60{ }^{\circ} \mathrm{C}$, after which increasing temperature reduces the fractional helicity from 60 to $15 \%$ with a $T_{\mathrm{m}}$ of $69.7 \pm 0.7^{\circ} \mathrm{C}$ and a transition width, $\Delta T$, of $9.8^{\circ} \mathrm{C}$. The near-UV CD ellipticity is also relatively unperturbed up to $60{ }^{\circ} \mathrm{C}$ (Figure 2B,D) and is eliminated with a $T_{\mathrm{m}}\left(65.5 \pm 0.7^{\circ} \mathrm{C}\right)$ and a $\Delta T\left(7.5^{\circ} \mathrm{C}\right)$ that are only slightly lower than those measured by far-UV CD. The heating rates for the far- and near-UV CD experiments were 0.43 and $0.28{ }^{\circ} \mathrm{C} / \mathrm{min}$, respectively. Increasing the rate of heating to $1{ }^{\circ} \mathrm{C} / \mathrm{min}$ increased the melting points of the far- and near-UV CD transitions to $75 \pm 1.1$ and $71 \pm 2$ ${ }^{\circ} \mathrm{C}$, respectively. This result is in reasonably good agreement with the observations of Sehgal et al. (62), who measured the dependence of $T_{\mathrm{m}}$ on the rate of heating in the E. coli AIDA (adhesin involved in diffusion adherence) protein. They reported that the $T_{\mathrm{m}}$ of AIDA is elevated by $6{ }^{\circ} \mathrm{C}$ when the scan rate is increased from 0.25 to $1{ }^{\circ} \mathrm{C} / \mathrm{min}$ but that the $T_{\mathrm{m}}$ is more sensitive to heating rates below $0.66{ }^{\circ} \mathrm{C} / \mathrm{min}$ and less sensitive at rates above this.

The thermal stability of the tertiary structure was also monitored by Trp fluorescence; elevated temperatures progressively quench the Trp fluorescence, and a small red shift from 329 to $333 \mathrm{~nm}$ is detected in the spectra at temperatures above $60{ }^{\circ} \mathrm{C}$ (Figure S2A). Thus, as the tertiary structure unfolds, there is a slight increase in accessibility to water of one or more of the Trp residues. Taken together with the electrophoresis data (Figure 1A,B), the CD and fluorescence results suggest that the thermal transition in DDM involves a concomitant loss of secondary, tertiary, and quaternary structure with a transition midpoint between 66 and $70{ }^{\circ} \mathrm{C}$.

Compared to the protein dissolved in DDM, the glycerol facilitator secondary and tertiary structures in LMPC show significantly higher thermostability. When measured at a heating rate of $1{ }^{\circ} \mathrm{C} / \mathrm{min}$, the secondary structure unfolds with a $T_{\mathrm{m}}$ of $86.9 \pm 11.5^{\circ} \mathrm{C}$; however, the transition width $(\Delta T)$ is wide $\left(15.1^{\circ} \mathrm{C}\right)$, suggesting helices with varying thermal stability (panels A and B of Figure S1). According to near-UV CD, the tertiary structure of the protein unfolds at $75.0 \pm 1.5^{\circ} \mathrm{C}$ with a transition width $(\Delta T)$ of $9.2^{\circ} \mathrm{C}$ in LMPC (Figure $2 \mathrm{~F}$ ). These measurements were made by heating the samples at $1^{\circ} \mathrm{C} / \mathrm{min}$,
A

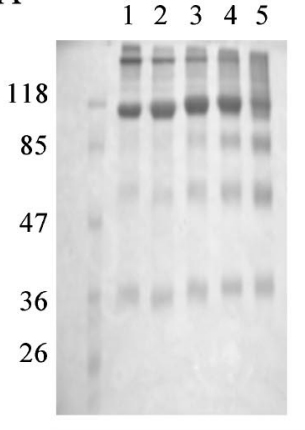

B
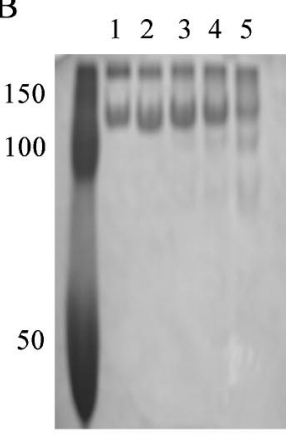

C

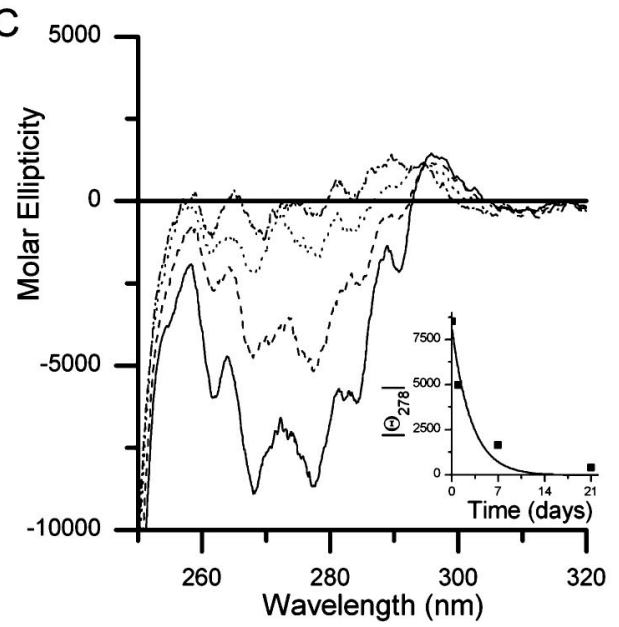

FIGURE 3: Effects of urea on the quaternary and tertiary structure of DDM-solubilized GF at $\mathrm{pH}$ 7. Protein was incubated in urea for 3 weeks and then analyzed by (A) SDS-PAGE and (B) BN-PAGE: lane 1, $0 \mathrm{M}$ urea; lane 2, $2 \mathrm{M}$ urea; lane 3, $4 \mathrm{M}$ urea; lane 4, $6 \mathrm{M}$ urea; lane $5,8 \mathrm{M}$ urea. (C) Time dependence of unfolding of 55.4 $\mu \mathrm{M}$ GF tertiary structure by $8 \mathrm{M}$ urea: $(-) 1 \mathrm{~h},(--) 24 \mathrm{~h},(\cdots) 7$ days, and (-・) 21 days. The inset shows the fit of the change in ellipticity at $268 \mathrm{~nm}$ to an exponential decay as described in Methods.

the same rate used for the DDM experiments and the same rate used by Sehgal et al. (62). Measurements were also taken at $0.5^{\circ} \mathrm{C} / \mathrm{min}$ and resulted in a lowering of the near-UV CD $T_{\mathrm{m}}$ by $1.6^{\circ} \mathrm{C}$. Thus, the protein in LMPC appears slightly less sensitive to heating rate than in DDM. Overall, LMPC appears to stabilize the secondary structure more than the tertiary structure and lowers the cooperativity of the unfolding between the levels of structure. Interestingly, the quaternary structure appears to unfold concomitant with the secondary structure rather than the tertiary structure as the $T_{\mathrm{m}}$ is well above $80^{\circ} \mathrm{C}$.

Urea is a common protein denaturant used to measure the stability of many water-soluble proteins and has recently been shown to reversibly unfold a $\beta$-barrel protein (11). Initial experiments with DDM-solubilized GF indicated a time dependence of the effects of urea, and in an attempt to establish equilibrium conditions, the protein was incubated in various concentrations of urea for 3 weeks. Panels A and B of Figure 3 show the effects of additions of urea on the DDM-solubilized protein quaternary structure. According to SDS-PAGE, low concentrations of urea (2-4 M; lanes 2 and 3 in Figure $3 \mathrm{~A}$ ) have an only minor effect on the amount of tetramer present in the solution. Small increases in monomer, dimer, and trimer are observed, but the most notable change is the significant loss of octamer. After incubation for 3 weeks in $8 \mathrm{M}$ urea (Figure $3 \mathrm{~A}$, lane 5 ), the tetramer is nearly absent, the levels of monomer, dimer, and trimer have increased substantially, and the amount 
A

$\begin{array}{lllllllll}1 & 2 & 3 & 4 & 5 & 6 & 7 & 8 & 9\end{array}$

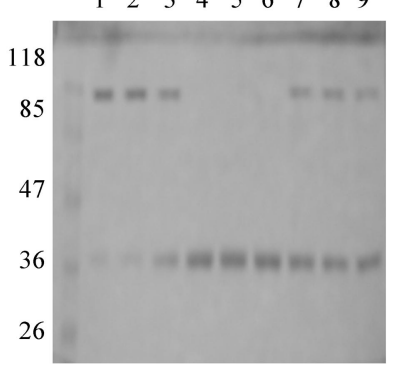

$\mathrm{B}$

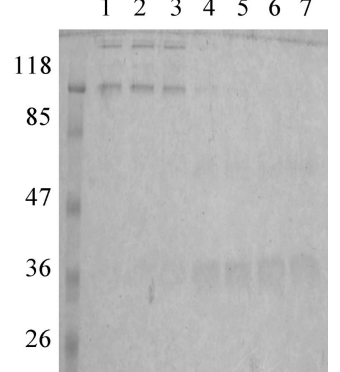

FIGURE 4: Effects of increasing and decreasing the $\mathrm{pH}(\mathrm{A})$ and incubation with SDS at $\mathrm{pH} 4$ (B) on the quaternary structure of DDM-solubilized GF. (A) SDS-PAGE: lane 1, pH 7.8; lane 2, $\mathrm{pH}$ 7.0; lane 3, pH 6.0; lane 4, $\mathrm{pH} 5.0$; lane 5, $\mathrm{pH} 4.0$; lane 6, $\mathrm{pH}$ 5.0; lane 7, pH 6.0; lane 8, $\mathrm{pH} 7.0$; lane 9, $\mathrm{pH}$ 7.8. (B) SDS-PAGE: lane 1, 0 mM SDS; lane 2, 2 mM SDS; lane 3, 5 mM SDS; lane 4, $10 \mathrm{mM}$ SDS; lane 5, $20 \mathrm{mM}$ SDS; lane 6, $40 \mathrm{mM}$ SDS; lane 7, $60 \mathrm{mM}$ SDS.

of octamer is greatly reduced. In addition, material electrophoresing between the tetramer and octamer appears that is likely an unfolded aggregate soluble in high concentrations of SDS and urea. BN-PAGE of the same samples is shown in Figure 3B. The BN gels are less sensitive to the unfolding induced by urea at low concentrations because in the absence of SDS the low-molecular weight species cannot be observed on the gels; presumably, they form aggregates too large to enter the gel. It is also likely that in the absence of SDS the tetramer is more resistant to dissociation in low concentrations of urea. However, at 6 and $8 \mathrm{M}$ urea, the unfolding of the tetramer and octamer is evident from their diminishing bands on the $\mathrm{BN}$ gel and from the very faint bands that appear to be trimer and dimer that appear. The latter are soluble in small amounts because of the high concentrations of urea present, whereas in DDM alone, they are not observed.

Figure $3 \mathrm{C}$ shows another indication of the resistance of the protein to denaturation by urea. Incubation of the DDMsolubilized GF in $8 \mathrm{M}$ urea for 1 day causes very little change in the near-UV CD spectrum. However, over the course of 21 days, the added urea reduces the level of tertiary structure with an exponential unfolding rate constant of $(4 \pm 1) \times$ $10^{-6} \mathrm{~s}^{-1}$. The high concentrations of urea required to unfold the protein and the slow unfolding rate both suggest a high thermodynamic stability of the protein in DDM.

Influence of $p H$ and SDS on GF Structure. The electrophoregram in Figure 4A shows the influence of $\mathrm{pH}$ on the quaternary structure of DDM-solubilized GF initially prepared at $\mathrm{pH}$ 7.8. Lane 1 shows that the protein is predominantly tetrameric at $\mathrm{pH} 7.8$ with a small amount of monomer present on SDS-PAGE. Lowering the $\mathrm{pH}$ to 7.0 (lane 2) causes little change in the oligomer structure, but at $\mathrm{pH} 6.0$ (lane 3), the tetramer band is diminished and the monomer band increased, indicating partial dissociation of the tetramer

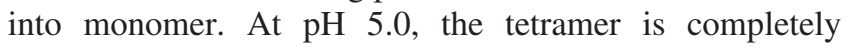
converted to monomer (Figure 4A, lane 4), and lowering the $\mathrm{pH}$ to 4.0 causes no further change in the oligomerization state (Figure 4A, lane 5). It is worth noting that the lanes containing monomer show no dimer and trimer protein, suggesting that the monomer is in an unaggregated and partially folded state. To determine if the acid-induced unfolding of the tetramer could be reversed, the $\mathrm{pH}$ of the same protein preparation was elevated and the refolding monitored by SDS-PAGE. When the $\mathrm{pH}$ is increased from
4.0 to 5.0 (lane 6), only monomeric DDM-solubilized protein is observed in accord with what was observed when the $\mathrm{pH}$ was lowered from pH 6.0 to 5.0 (lane 4). When the $\mathrm{pH}$ is increased from 5.0 to $6.0,60 \%$ of the monomer is restored to the tetramer state (lane 7), indicating substantial reversibility of the $\mathrm{pH}$-induced unfolding. Elevation of the $\mathrm{pH}$ to 7.0 (lane 8) and 7.8 (lane 9) causes little conversion of monomer to tetramer. It seems unlikely that the tetramer band is an unfolded protein aggregate as no dimer or trimer appears on the electropherogram. Note also that some of the protein that is irreversibly unfolded appears on the gels as a high- $M_{\mathrm{r}}$ aggregate near the top of the gel.

Whenever SDS-PAGE is used to monitor quaternary structure, the protein is subjected to approximately $60 \mathrm{mM}$ SDS from the sample treatment buffer. In an attempt to separate the effects of $\mathrm{pH}$ and SDS on the $\mathrm{pH}$-induced unfolding, an SDS titration was carried out. DDM-solubilized GF was incubated at $\mathrm{pH} 4.0$ with $0-60 \mathrm{mM}$ SDS for $10 \mathrm{~min}$, and then the $\mathrm{pH}$ was increased to 7.0. In the absence of SDS (Figure 4B, lane 1), GF electrophoreses as a tetramer with very little monomer observed when the $\mathrm{pH}$ is returned to 7.0. Interestingly, cycling the $\mathrm{pH}$ induces the formation of small amounts of octameric protein. The presence of $2 \mathrm{mM}$ SDS has no measurable effect on the oligomeric state of the protein (lane 2), whereas at $5 \mathrm{mM}$ SDS (lane 3), monomer and dimer can be observed in the preparation. At $10 \mathrm{mM}$ SDS (lane 4), the majority of tetrameric and octameric GF is lost and significant amounts of both monomer and dimer are observed. Further increases in SDS concentration to 20, 40 , and $60 \mathrm{mM}$ (Figure 3, lanes 5-7, respectively) continue to decrease the levels of the tetrameric and octameric species while increasing the levels of the monomeric and dimeric forms of the $\mathrm{pH} 4 \mathrm{DDM}$-solubilized GF. These experiments suggest that the SDS present in the SDS-PAGE sample buffer induced the tetramer dissociation observed in Figure $4 \mathrm{~A}$, and BN-PAGE confirmed that in the absence of SDS no monomer is formed at $\mathrm{pH} 4$ (data not shown). These results show that there is a pH-dependent change in the structure of the protein making it more susceptible to SDS unfolding but that these changes are at least partially reversible.

The effects of $\mathrm{pH}$ on the structure of the GF tetramer dissolved in LMPC are markedly different compared to the effects on the protein dissolved in DDM. SDS-PAGE (Figure S3A) shows the $\mathrm{pH}$-dependent replacement of the tetramer with monomer, dimer, and trimer in LMPC, indicative of irreversibly unfolded protein, whereas in DDM, only monomeric protein is observed at low $\mathrm{pH}$. BN gels (not shown) confirm the sensitivity of the LMPC-solubilized protein to $\mathrm{pH}$. At $\mathrm{pH} 4$, the tetramer has almost completely disappeared from the gel, and in its place are low-molecular weight species (monomer, dimer, and trimer) and a very high-molecular weight species which enters the top of the stacking gel.

Changes in secondary and tertiary structures brought about by lowering the $\mathrm{pH}$ were investigated spectroscopically. In DDM and in LMPC, pH caused essentially no change in the secondary structure of the protein between $\mathrm{pH} 7.8$ and 3 as judged by far-UV CD (panels A and B of Figure S4). Similarly, lowering the $\mathrm{pH}$ of the protein dissolved in DDM to $\mathrm{pH} 4$ diminishes only slightly (20\%) both the positive and negative ellipticity in the near-UV CD spectrum (Figure 


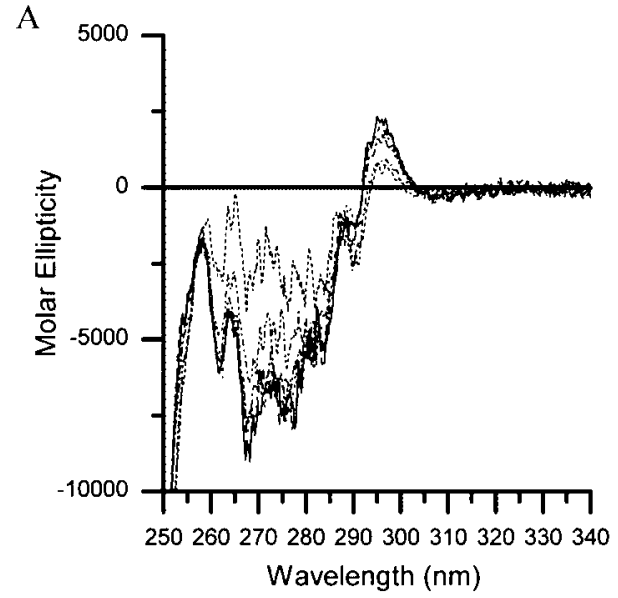

$\mathrm{B}$

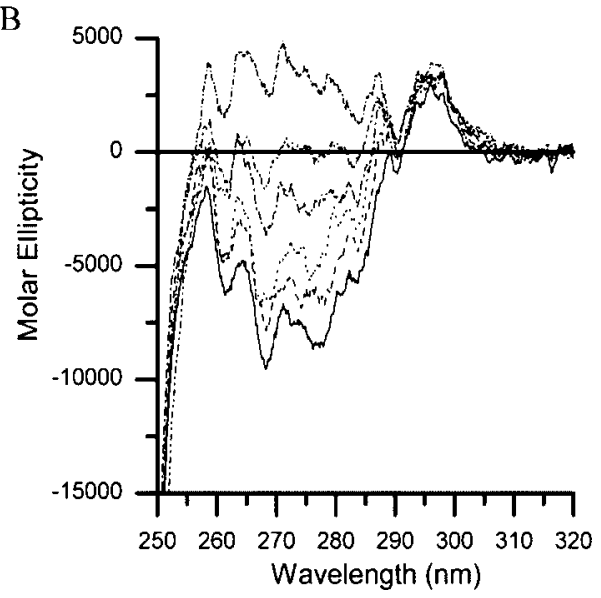

FIGURE 5: Effects of $\mathrm{pH}$ on the tertiary structure of DDM- and

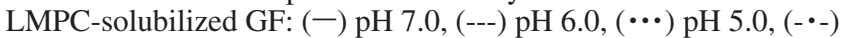
$\mathrm{pH} 4.0$, and (--) pH 3.0. (A) GF $(69 \mu \mathrm{M})$ in DDM, with tertiary structure monitored by near-UV CD. (B) GF $(80 \mu \mathrm{M})$ in LMPC, with tertiary structure monitored by near-UV CD.

5A). However, between $\mathrm{pH} 4$ and 3, a more significant change occurs eliminating most of the near-UV CD signal intensity (Figure 5A). In contrast, in LMPC (Figure 5B), the near-UV CD band at $295 \mathrm{~nm}$ increases in intensity as the $\mathrm{pH}$ is lowered and the ellipticity between 255 and $290 \mathrm{~nm}$ changes from negative at $\mathrm{pH} 7$ to positive at $\mathrm{pH}$ 3. Also notable is the significant change in the CD signal between $\mathrm{pH} 7$ and 4 indicating a greater sensitivity to the acidic $\mathrm{pH}$ of the protein in LMPC.

The effects of $\mathrm{pH}$ on the fluorescence of the protein were also measured (panels A and B of Figure S5). In DDM, between $\mathrm{pH} 7$ and 5, the Trp emission is quenched by $15 \%$ but there is no detectable change in the position of the emission maximum. However, between $\mathrm{pH} 5$ and 4, the quantum yield is restored to slightly more than its original value and the peak maximum shifts $4 \mathrm{~nm}$ to the red. Between $\mathrm{pH} 4$ and 3, the fluorescence is quenched by $30 \%$ but the emission maximum remains at $333 \mathrm{~nm}$. In LMPC, decreasing the $\mathrm{pH}$ continuously quenches the Trp emission between $\mathrm{pH}$ 7 and 4; the emission maximum shifts to the red by $2 \mathrm{~nm}$ between $\mathrm{pH} 7$ and 6 and shifts a further $2 \mathrm{~nm}$ between $\mathrm{pH}$ 6 and 5. There is little change in either the quantum yield or the emission maximum between $\mathrm{pH} 4$ and 3 . These changes likely reflect direct effects of the protonation of different side chains in the local environments of the five Trp residues as well as indirect effects of the unfolding of the tertiary structure as the $\mathrm{pH}$ is decreased.
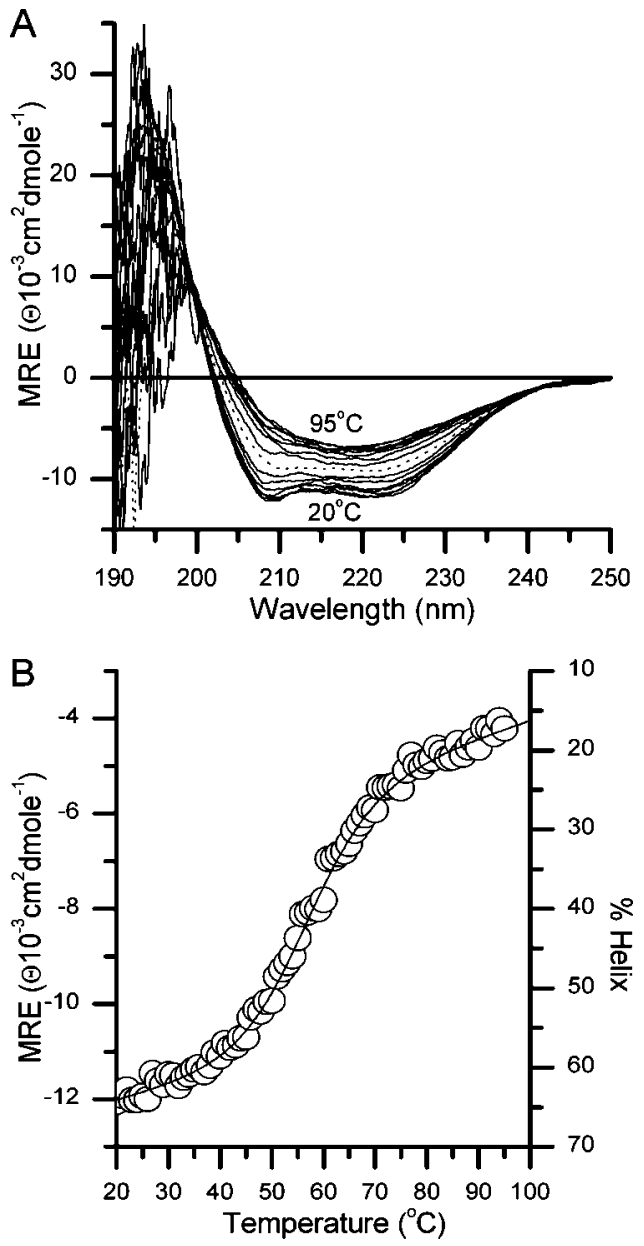

FIGURE 6: Characterization of the $\mathrm{pH}$ 3.0 DDM-solubilized GF molten globule by CD. (A) Thermal denaturation of secondary structure monitored by far-UV CD $(2.6 \mu \mathrm{M})$. Spectra were collected between 20 and $95{ }^{\circ} \mathrm{C}$ in $5{ }^{\circ} \mathrm{C}$ intervals. The dotted line is the 55 ${ }^{\circ} \mathrm{C}$ spectrum. (B) MRE at $209 \mathrm{~nm}$ as a function of temperature fit to a two-state unfolding transition as described in Methods. The fractional helicity was determined by deconvolution as described in Methods, and the results agree with the scale on the right side of Figure $6 \mathrm{~B}$ within $\pm 5 \%$.

At $\mathrm{pH} 3$, the GF electrophoreses as a monomer via SDS-PAGE and as a mixture of monomer and high-molecular weight oligomers via BN-PAGE (not shown), retains its native content of $\alpha$-helix (Figure S4A), but has significantly reduced tertiary structure content in DDM (Figure 5A). Mildly acidic conditions ( $\mathrm{pH} 3-4$ ) have been used to produce molten globule states of a large number of water-soluble proteins (70). The stability of the $\mathrm{pH} 3$ state of the glycerol facilitator dissolved in DDM was studied by unfolding it with heat. In Figure 6A, the $\mathrm{CD}$ spectra show that the protein at low $\mathrm{pH}$ unfolds with a significantly lower $T_{\mathrm{m}}\left(56.9 \pm 1.4^{\circ} \mathrm{C}\right)$ and over a wider temperature range $\left(\Delta T=23.4^{\circ} \mathrm{C}\right)$ than the neutral-pH form. Deconvolution of the CD spectra indicates that at $95^{\circ} \mathrm{C} 18 \%$ of the core of the $\alpha$-helix is still folded in the $\mathrm{pH} 3$ state of the protein. The thermal unfolding was also monitored by fluorescence; as the temperature is elevated, there is a progressive quenching of Trp fluorescence but no change in the emission maximum at $333 \mathrm{~nm}$ (data not shown). SDS-PAGE shows that, similar to the case for the high-pH form of the protein, thermal unfolding of the low-pH form causes nonspecific aggregation of the protein into high-molecular weight oligomers (data not shown). 


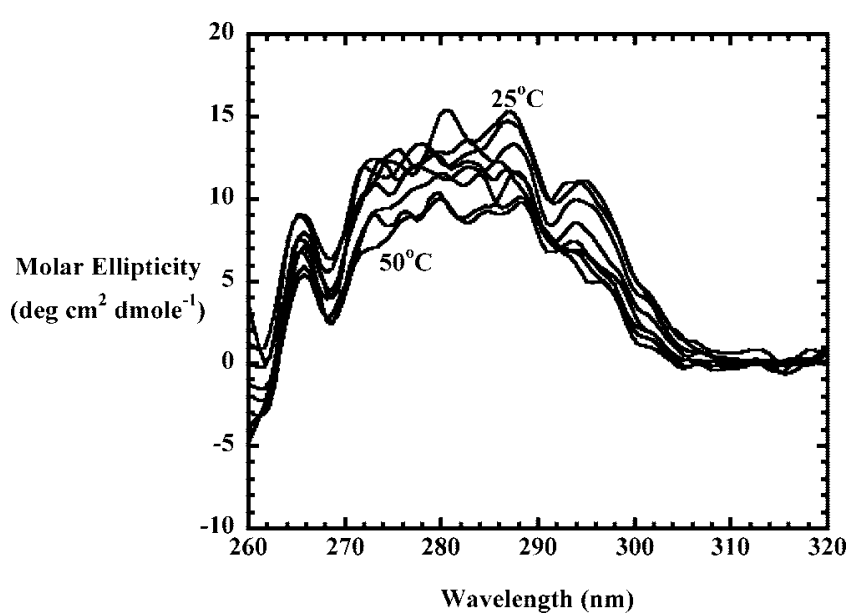

FIGURE 7: Effect of temperature on the near-UV CD spectra of GF dissolved in SDS. Protein was purified as described previously (27), and the concentration was $77 \mu \mathrm{M}$. Spectra were recorded at 20 and $25^{\circ} \mathrm{C}$ and between 30 and $80{ }^{\circ} \mathrm{C}$ in $10{ }^{\circ} \mathrm{C}$ intervals.

Glycerol Facilitator in SDS. We have previously shown that GF prepared in SDS and eluted from the $\mathrm{Ni}^{2+}$ resin at $\mathrm{pH} 4.2$ electrophoreses predominantly as a monomeric protein on SDS-PAGE and contains an $\alpha$-helix content of $48 \%$ (53\% if one accounts for the affinity tag) (27). The $\alpha$-helix in low-pH-eluted, SDS-solubilized protein is thermally stable up to $50{ }^{\circ} \mathrm{C}$, and at $70{ }^{\circ} \mathrm{C}$ the protein still retains $40 \%$ of its helix content (data not shown). Thus, in SDS the $\alpha$-helices are thermally very stable which has been noted for several other membrane proteins (12). Near-UV CD spectra of GF dissolved in SDS at various temperatures are shown in Figure 7. The spectra are similar to that observed for the protein at $\mathrm{pH} 3$ in LMPC (Figure 5B). The weak positive ellipticity and the less well-defined absorption bands suggest some transient asymmetry in the environments of the aromatic residues. Increasing the temperature does not eliminate the spectrum, and there is therefore no evidence of a two-state unfolding transition. The protein in SDS thus appears to reside in a compact association of $\alpha$-helices retaining much of its native secondary structure, has an altered tertiary structure, but retains none of its quaternary structure.

\section{DISCUSSION}

GF Oligomers. In cells, membrane protein folding and the stability of the native state depend on a complex interplay among amino acid sequence, water, lipid hydrocarbon, lipid head groups, and the translocon. Despite the importance of environmental variables, it is unlikely that the native states of membrane proteins are kinetically trapped intermediates determined by the folding pathway. Rather, just as in the case of water-soluble proteins that fold with the aid of chaperones (71), membrane proteins likely reside at thermodynamic free energy minima dictated mainly by amino acid sequence. In vitro folding studies of membrane proteins can therefore provide information about the intra- and intermolecular forces that stabilize the native fold if it can be isolated (12). In contrast to earlier reports (27, 38-44), we have shown here that the glycerol facilitator exists as a stably folded tetramer in solutions of the neutral detergent DDM and in zwitterionic LMPC. That the tetramer is the native state of the protein is supported by observations of tetramers in the crystalline state by X-ray diffraction (26) and by cryoelectron microscopic observations of twodimensional crystals of protein reconstituted in E. coli lipid (42). There is some evidence to suggest that the glycerol facilitator exists in close association at the inner membrane (72) with the E. coli glycerol kinase, which is active both as a dimer and as a tetramer. A 1:1 association between the two protein tetramers would provide the most efficient pathway for transferring glycerol from the facilitator to the kinase, preventing loss from the cytoplasm of membranepermeable glycerol $(26,73)$.

In addition to the tetramer, we also observe varying amounts of octameric glycerol facilitator in the detergent preparations. The octamers appear to be less stable than the tetramers as heat and urea dissociate the octamer under conditions milder than those used for the tetramer. Scanningtunneling electron microscopy of freeze-dried solubilized GF showed that significant amounts of octamer coexist with tetramers and even a small fraction of dodecamer (42). Octamers and higher associations of aquaporin- 0 have been observed by BN-PAGE, by analytical ultracentrifugation, and in loosely packed three-dimensional crystals (74). The structure of the aquaporin- 0 octamer suggests that a plausible function is the formation of cell contacts between closely apposed lens cells. Weak self-association of GF tetramers in detergent preparations suggests the possibility that the GF protein may cluster in the inner membrane of $E$. coli and that the clustering may be functionally significant (75).

GF Thermal Stability. Most membrane proteins aggregate irreversibly upon thermal unfolding, precluding a rigorous thermodynamic treatment. However, because unfolding and oligomerization are often coupled, the onset of oligomerization can give an indication of thermal stability (9) and may yield valuable information about the folding pathway. A recent review of membrane protein stability indicates that helical membrane proteins unfold with low enthalpies of denaturation compared to water-soluble proteins, that transition midpoints depend on the nature of the solubilizing detergent or lipid, and that a core of highly stable $\alpha$-helical structure often remains at elevated temperatures $(9,76)$. For example, bacteriorhodopsin unfolds with a $T_{\mathrm{m}}$ of $100{ }^{\circ} \mathrm{C}$ in purple membranes, leaving much of its helix content intact, whereas the $T_{\mathrm{m}}$ is reduced to $80^{\circ} \mathrm{C}$ in detergent (for a review, see ref 76). Cytochrome oxidase unfolds in dodecyl maltoside in two stages with $T_{\mathrm{m}}$ values of 47 and $67^{\circ} \mathrm{C}$, leaving $70 \%$ of its helix content intact at high temperatures (77). Similar results with other proteins suggest that the surface-exposed loops and domains of helical membrane proteins unfold at lower temperatures, producing a molten globule-like structure of loosely associated, thermal stable $\alpha$-helices. In general, such studies support the models of in vitro (20-23) and in vivo $(9,10,14-16)$ MP folding in which tertiary structure forms by an association of preformed $\alpha$-helices.

In this work, far-UV circular dichroism (Figure 2A) shows that the helix contents of the glycerol facilitator measured in DDM and in LMPC solutions at neutral $\mathrm{pH}$ and $25^{\circ} \mathrm{C}$ are identical and in close agreement with the structure observed in the crystals (26); fluorescence (panels A and B of Figure S2) and near-UV circular dichroism (Figure 2B,E) show that the tertiary structures are nearly identical in the two detergent solutions. However, significant differences are observed in the sensitivity of the protein to heat and acid in 
the two detergents. In DDM, the protein appears to unfold secondary, tertiary, and quaternary structures in a more or less cooperative transition between 71 and $75^{\circ} \mathrm{C}$. In LMPC, all levels of structure are more thermally stable than in DDM and the unfolding is less cooperative. The melting points of the secondary structure $\left(T_{\mathrm{m}}=87^{\circ} \mathrm{C}\right)$ and quaternary structure $\left(T_{\mathrm{m}}>80^{\circ} \mathrm{C}\right)$ are similar and significantly higher than that of the tertiary structure $\left(T_{\mathrm{m}}=75^{\circ} \mathrm{C}\right)$; however, the secondary structure unfolding transition $\left(\Delta T=15^{\circ} \mathrm{C}\right)$ is broad, suggesting helices with varying stability. The lower stability of the protein in DDM is also indicated by the lower thermally stable helix content remaining at $95{ }^{\circ} \mathrm{C}$ in DDM (14\%) compared to LMPC (22\%). The loss of tertiary structure before secondary structure in LMPC and the presence of a core of thermally stable helices in both detergents support the standard view that the connecting loops are more thermally labile than the $\alpha$-helices. However, the cooperative unfolding of much of the helix content along with the tertiary and quaternary structure in DDM indicates the influence that detergent can have on the unfolding pathway. Interestingly, high concentrations of urea unfold the protein dissolved in DDM only very slowly (Figure 3). It has been argued that urea does not disrupt hydrophobic interactions (78), and this suggests that hydrophobic interactions between the protein monomers play a major role in stabilizing the protein structure.

A possible explanation of the higher thermal stability of the GF in LMPC compared to DDM is that the phosphocholine headgroup provides an electrostatic environment that is better matched to $\mathrm{GF}$ at $\mathrm{pH} 7$ than the neutral maltoside. This seems likely in light of the high abundance $(>80 \mathrm{~mol}$ $\%$ ) of phosphatidylethanolamine in the E. coli inner membrane which is iso-Coulombic with phosphatidylcholine. In LMPC, the quaternary structure of the GF appears to be more thermally stable than the tertiary structure. This suggests that, in vivo, the tetramer may form by the association of molten globule-like structures that contain native $\alpha$-helices but no fixed tertiary structure and that compact tertiary folds form only in the assembled tetramer. This pathway would assign a chaperone function to each of the monomers and highlights the importance of the tetramer in stabilization of the protein tertiary structure. Such a mechanism may be widespread as many membrane proteins are oligomeric and may require multiple protein-protein contacts for formation and stabilization of well-packed tertiary cores. Dimeric pro-caspase3 , a water-soluble protein, has been shown to unfold to an associated dimer intermediate, and the stability of the dimer contributes a significant fraction of the conformational free energy of the protein (79).

The significant difference in stability between bacteriorhodopsin and the glycerol facilitator might be due to the structures of the proteins. The seven-helix bundle protein BR consists of seven $\alpha$-helices surrounding a central retinal, and the bound hydrophobic prosthetic group likely contributes to the added stability. The GF also consists of a bundle of seven transmembrane $\alpha$-helices; however, one helix is comprised of two half-helices that span only half the bilayer, returning to the surface of the protein as an irregularly folded loop (26). In the absence of compensating interactions, the two half-helices are expected to be less stable than a full TM helix because of a smaller fraction of central residues fixed by two helical H-bonds per residue and a reduced number of stabilizing dipole-dipole interactions. However, this structural difference cannot explain the apparent greater stability of the aquaporins in solution (45-51) compared to the glycerol facilitator $(27,38-44)$ as the protein folds are very similar. A full explanation will require a more detailed study of the stability of the aquaporins.

GF pH Stability. The GF shows significantly different stability to acid $\mathrm{pH}$ in the two different detergents that were tested. In zwitterionic LMPC, the protein irreversibly unfolds and aggregates as the $\mathrm{pH}$ is lowered from 7 to 4 (Figure S3A). Although the charge state of the detergent phosphocholine is unchanged over this $\mathrm{pH}$ range, the buildup of positive charge on the protein must be incompatible with the charges on the detergent headgroup. In the neutral detergent DDM, all levels of structure appear to remain folded down to $\mathrm{pH} 4$. However, at $\mathrm{pH} 4$ in DDM, the tetramer protein is less stable than at $\mathrm{pH} 7$ as small additions of SDS are enough to dissociate it to a monomeric state (Figure 4B). The conformational change must be subtle as it can be detected only by changes in Trp fluorescence (Figure S5A) and minor changes in the near-UV CD spectrum (Figure 3C). Furthermore, the structural changes that occur in the protein between $\mathrm{pH} 7$ and 4 appear to be partially reversible, whereas decreasing the $\mathrm{pH}$ to 3 irreversibly unfolds the tetramer and protein tertiary structure. At $\mathrm{pH} 3$ in DDM, the protein is monomeric, retains its native helix content, but has lost most of its tertiary organization. This "molten globule-like" association of helices has a lower thermal stability than the native tetramer at neutral $\mathrm{pH}$ but still retains $18 \%$ of its native helix core at $95{ }^{\circ} \mathrm{C}$. Mildly acidic conditions ( $\mathrm{pH} 3-4)$ have been used to produce molten globule states of a large number of water-soluble proteins (70), and the equilibrium molten globule is thought to be an analogue of an important kinetic intermediate in the folding pathway of many water-soluble proteins (70). It has also been shown to be an important intermediate on the membrane insertion pathway of the colicin Ia channel domain (80).

The reversible unfolding of several membrane proteins has been accomplished with the use of SDS, but recently, it has been pointed out that SDS has a strong helix stabilizing capacity and that chemical unfolding with SDS is unlikely to produce a disordered polypeptide (12). Instead, membrane proteins in SDS likely exist in condensed states with their tertiary structure disrupted by intercalation of SDS molecules between the TM helices. The near-UV CD spectrum of the GF dissolved in SDS shows mainly positive bands with significant band structure suggestive of the maintenance of some tertiary contacts. The spectrum in SDS is strikingly similar to that observed in LMPC at $\mathrm{pH} 3$, suggesting that in LMPC at low $\mathrm{pH}$ the protein forms a condensed unfolded structure similar to that present in SDS.

These results show that the glycerol facilitator is less thermally stable than bacteriorhodopsin but more stable than cytochrome oxidase. In the case of the glycerol facilitator, the measured stability is in good agreement with the observations of a tightly packed three-dimensional structure and low-temperature $B$-factors by X-ray diffraction (26). The results also agree with calculations of root-mean-square deviations of $\mathrm{C}^{\alpha}$ atoms during molecular dynamics simulations that indicate only very minor conformational changes during the passage of glycerol through the pore $(81,82)$. The molecular dynamics simulations indicate that there is 
no cooperativity between the subunits of the tetramer during glycerol passage (81), and this suggests that the tetramers play a structural role in stabilizing the monomer conformation in the hydrophobic membrane. The molecular dynamics simulations also point out that the stability of the pore conformation is critical both for the conduction of glycerol and for the selectivity of the pore for glycerol over water (81). Kinetically and thermodynamically stable preparations of membrane proteins in detergent may be amenable to structure and dynamics analysis by multinuclear NMR TROSY experiments (83) if sufficient deuterium-labeled protein can be prepared at concentrations of $200-500 \mu \mathrm{M}$ (84).

\section{SUPPORTING INFORMATION AVAILABLE}

Thermal unfolding of secondary structure LMPC-solubilized GF (Figure S1), thermal unfolding of GF monitored by tryptophan fluorescence (Figure S2), effects of $\mathrm{pH}$ on the quaternary structure of GF dissolved in LMPC (Figure S3), effects of $\mathrm{pH}$ on the far-UV CD spectra of GF (Figure S4), and effects of $\mathrm{pH}$ on the tryptophan fluorescence of GF (Figure S5). This material is available free of charge via the Internet at http://pubs.acs.org.

\section{REFERENCES}

1. Grisshammer, R., and Tate, C. G. (1995) Overexpression of integral membrane proteins for structural studies. Q. Rev. Biophys. 28, 315422.

2. Bowie, J. U. (2001) Stabilizing membrane proteins. Curr. Opin. Struct. Biol. 11, 397-402.

3. Drew, D., Froderberg, L., Baars, L., and de Gier, J. W. (2003) Assembly and overexpression of membrane proteins in Escherichia coli. Biochim. Biophys. Acta 1610, 3-10.

4. Daley, D. O., Rapp, M., Granseth, E., Melen, K., Drew, D., and von Heijne, G. (2005) Global topology analysis of the Escherichia coli inner membrane proteome. Science 308, 1321-1323.

5. Abramson, J., Smirnova, I., Kasho, V., Verner, G., Kaback, H. R., and Iwata, S. (2003) Structure and mechanism of the lactose permease of Escherichia coli. Science 301, 610-615.

6. Jiang, Y., Lee, A., Chen, J., Ruta, V., Cadene, M., Chait, B. T., and MacKinnon, R. (2003) X-ray structure of a voltage-dependent $\mathrm{K}^{+}$channel. Nature 423, 33-41.

7. Tsai, J., Taylor, R., Chothia, C., and Gerstein, M. (1999) The packing density in proteins: Standard radii and volumes. J. Mol. Biol. 290, 253-266.

8. Yeates, T. O., Komiya, H., Rees, D. C., Allen, J. P., and Feher, G. (1987) Structure of the reaction center from Rhodobacter sphaeroides R-26: Membrane-protein interactions. Proc. Natl. Acad. Sci. U.S.A. 84, 6438-6442.

9. Minetti, C. A., and Remeta, D. P. (2006) Energetics of membrane protein folding and stability. Arch. Biochem. Biophys. 453, 3253.

10. Mackenzie, K. R. (2006) Folding and stability of $\alpha$-helical integral membrane proteins. Chem. Rev. 106, 1931-1977.

11. Hong, H., and Tamm, L. K. (2004) Elastic coupling of integral membrane protein stability to lipid bilayer forces. Proc. Natl. Acad. Sci. U.S.A. 101, 4065-4070.

12. Renthal, R. (2006) An unfolding story of helical transmembrane proteins. Biochemistry 45, 14559-14566.

13. MacKenzie, K. R., Prestegard, J. H., and Engelman, D. M. (1997) A transmembrane helix dimer: Structure and implications. Science 276, 131-133.

14. Dalbey, R. E., and Chen, M. (2004) Sec-translocase mediated membrane protein biogenesis. Biochim. Biophys. Acta 1694, 3753.

15. Samuelson, J. C., Chen, M., Jiang, F., Moller, I., Wiedmann, M., Kuhn, A., Phillips, G. J., and Dalbey, R. E. (2000) YidC mediates membrane protein insertion in bacteria. Nature 406, 637-641.

16. Van den Berg, B., Clemons, W. M., Jr., Collinson, I., Modis, Y., Hartmann, E., Harrison, S. C., and Rapoport, T. A. (2004) X-ray structure of a protein-conducting channel. Nature 427, 36-44.
17. Hessa, T., Kim, H., Bihlmaier, K., Lundin, C., Boekel, J., Andersson, H., Nilsson, I., White, S. H., and von Heijne, G. (2005) Recognition of transmembrane helices by the endoplasmic reticulum translocon. Nature 433, 377-381.

18. Bogdanov, M., Heacock, P. N., and Dowhan, W. (2002) A polytopic membrane protein displays a reversible topology dependent on membrane lipid composition. EMBO J. 21, 2107-2116.

19. Jensen, M. O., and Mouritsen, O. G. (2004) Lipids do influence protein function: The hydrophobic matching hypothesis revisited. Biochim. Biophys. Acta 1666, 205-226.

20. Popot, J. L., and Engelman, D. M. (1990) Membrane protein folding and oligomerization: The two-stage model. Biochemistry 29, 40314037.

21. Popot, J. L., and Engelman, D. M. (2000) Helical membrane protein folding, stability, and evolution. Annu. Rev. Biochem. 69, 881-922.

22. Engelman, D. M., Chen, Y., Chin, C. N., Curran, A. R., Dixon, A. M., Dupuy, A. D., Lee, A. S., Lehnert, U., Matthews, E. E., Reshetnyak, Y. K., Senes, A., and Popot, J. L. (2003) Membrane protein folding: Beyond the two stage model. FEBS Lett. 555, 122-125.

23. White, S. H., and Wimley, W. C. (1999) Membrane protein folding and stability: Physical principles. Annu. Rev. Biophys. Biomol. Struct. 28, 319-365.

24. Agre, P., and Kozono, D. (2003) Aquaporin water channels: Molecular mechanisms for human diseases. FEBS Lett. 555, 72-78.

25. Borgnia, M., Nielsen, S., Engel, A., and Agre, P. (1999) Cellular and molecular biology of the aquaporin water channels. Annu. Rev. Biochem. 68, 425-458.

26. Fu, D., Libson, A., Miercke, L. J., Weitzman, C., Nollert, P., Krucinski, J., and Stroud, R. M. (2000) Structure of a glycerolconducting channel and the basis for its selectivity. Science 290, 481-486.

27. Manley, D. M., McComb, M. E., Perreault, H., Donald, L. J., Duckworth, H. W., and O'Neil, J. D. (2000) Secondary structure and oligomerization of the E. coli glycerol facilitator. Biochemistry 39, 12303-12311.

28. Heller, K. B., Lin, E. C., and Wilson, T. H. (1980) Substrate specificity and transport properties of the glycerol facilitator of Escherichia coli. J. Bacteriol. 144, 274-278.

29. Lin, E. C. C. (1984) Glycerol utilization by facilitated diffusion coupled to phosphorylation in bacteria, Plenum Publishing Corp., New York.

30. Calamita, G., Bishai, W. R., Preston, G. M., Guggino, W. B., and Agre, P. (1995) Molecular cloning and characterization of AqpZ, a water channel from Escherichia coli. J. Biol. Chem. 270, 2906329066.

31. Maurel, C., Reizer, J., Schroeder, J. I., Chrispeels, M. J., and Saier, M. H., Jr. (1994) Functional characterization of the Escherichia coli glycerol facilitator, GlpF, in Xenopus oocytes. J. Biol. Chem. 269, 11869-11872.

32. Sanders, O. I., Rensing, C., Kuroda, M., Mitra, B., and Rosen, B. P. (1997) Antimonite is accumulated by the glycerol facilitator GlpF in Escherichia coli. J. Bacteriol. 179, 3365-3367.

33. Elcock, A. H., and McCammon, J. A. (2001) Identification of protein oligomerization states by analysis of interface conservation. Proc. Natl. Acad. Sci. U.S.A. 98, 2990-2994.

34. Ponstingl, H., Kabir, T., Gorse, D., and Thornton, J. M. (2005) Morphological aspects of oligomeric protein structures. Prog. Biophys. Mol. Biol. 89, 9-35.

35. Faham, S., and Bowie, J. U. (2002) Bicelle crystallization: A new method for crystallizing membrane proteins yields a monomeric bacteriorhodopsin structure. J. Mol. Biol. 316, 1-6.

36. Belrhali, H., Nollert, P., Royant, A., Menzel, C., Rosenbusch, J. P., Landau, E. M., and Pebay-Peyroula, E. (1999) Protein, lipid and water organization in bacteriorhodopsin crystals: a molecular view of the purple membrane at $1.9 \AA$ resolution. Struct. Folding Des. 7, 909-917.

37. Pebay-Peyroula, E., Rummel, G., Rosenbusch, J. P., and Landau, E. M. (1997) X-ray structure of bacteriorhodopsin at $2.5 \AA$ from microcrystals grown in lipidic cubic phases. Science 277, 16761681.

38. Borgnia, M. J., and Agre, P. (2001) Reconstitution and functional comparison of purified GlpF and AqpZ, the glycerol and water channels from Escherichia coli. Proc. Natl. Acad. Sci. U.S.A. 98, 2888-2893.

39. Duchesne, L., Pellerin, I., Delamarche, C., Deschamps, S., Lagree, V., Froger, A., Bonnec, G., Thomas, D., and Hubert, J. F. (2002) Role of C-terminal domain and transmembrane helices 5 and 6 in function and quaternary structure of major intrinsic proteins: 
Analysis of aquaporin/glycerol facilitator chimeric proteins. J. Biol. Chem. 277, 20598-20604.

40. Lagree, V., Froger, A., Deschamps, S., Hubert, J. F., Delamarche, C., Bonnec, G., Thomas, D., Gouranton, J., and Pellerin, I. (1999) Switch from an aquaporin to a glycerol channel by two amino acids substitution. J. Biol. Chem. 274, 6817-6819.

41. Stahlberg, H., Braun, T., de Groot, B., Philippsen, A., Borgnia, M. J., Agre, P., Kuhlbrandt, W., and Engel, A. (2000) The 6.9-Å structure of GlpF: A basis for homology modeling of the glycerol channel from Escherichia coli. J. Struct. Biol. 132, 133-141.

42. Braun, T., Philippsen, A., Wirtz, S., Borgnia, M. J., Agre, P., Kuhlbrandt, W., Engel, A., and Stahlberg, H. (2000) The $3.7 \AA$ projection map of the glycerol facilitator GlpF: A variant of the aquaporin tetramer. EMBO Rep. 1, 183-189.

43. Bron, P., Lagree, V., Froger, A., Rolland, J. P., Hubert, J. F., Delamarche, C., Deschamps, S., Pellerin, I., Thomas, D., and Haase, W. (1999) Oligomerization state of MIP proteins expressed in Xenopus oocytes as revealed by freeze-fracture electron-microscopy analysis. J. Struct. Biol. 128, 287-296.

44. Duchesne, L., Deschamps, S., Pellerin, I., Lagree, V., Froger, A., Thomas, D., Bron, P., Delamarche, C., and Hubert, J. F. (2001) Oligomerization of water and solute channels of the major intrinsic protein (MIP) family. Kidney Int. 60, 422-426.

45. Aerts, T., Xia, J. Z., Slegers, H., de Block, J., and Clauwaert, J. (1990) Hydrodynamic characterization of the major intrinsic protein from the bovine lens fiber membranes. Extraction in n-octyl- $\beta$-Dglucopyranoside and evidence for a tetrameric structure. J. Biol. Chem. 265, 8675-8680.

46. Konig, N., Zampighi, G. A., and Butler, P. J. (1997) Characterisation of the major intrinsic protein (MIP) from bovine lens fibre membranes by electron microscopy and hydrodynamics. J. Mol. Biol. 265, 590-602.

47. Smith, B. L., and Agre, P. (1991) Erythrocyte Mr 28,000 transmembrane protein exists as a multisubunit oligomer similar to channel proteins. J. Biol. Chem. 266, 6407-6415.

48. Verbavatz, J. M., Brown, D., Sabolic, I., Valenti, G., Ausiello, D. A., Van Hoek, A. N., Ma, T., and Verkman, A. S. (1993) Tetrameric assembly of CHIP28 water channels in liposomes and cell membranes: A freeze-fracture study. J. Cell Biol. 123, 605618.

49. Kamsteeg, E. J., Wormhoudt, T. A., Rijss, J. P., van Os, C. H., and Deen, P. M. (1999) An impaired routing of wild-type aquaporin-2 after tetramerization with an aquaporin-2 mutant explains dominant nephrogenic diabetes insipidus. EMBO J. 18, 2394-2400.

50. Beuron, F., Le Caherec, F., Guillam, M. T., Cavalier, A., Garret, A., Tassan, J. P., Delamarche, C., Schultz, P., Mallouh, V., and Rolland, J. P. (1995) Structural analysis of a MIP family protein from the digestive tract of Cicadella viridis. J. Biol. Chem. 270, 17414-17422.

51. Ringler, P., Borgnia, M. J., Stahlberg, H., Maloney, P. C., Agre, P., and Engel, A. (1999) Structure of the water channel AqpZ from Escherichia coli revealed by electron crystallography. J. Mol. Biol. 291, 1181-1190.

52. Manley, D., and O'Neil, J. D. (2003) Preparation of glycerol facilitator for protein structure and folding studies in solution. Methods Mol. Biol. 228, 89-101.

53. Vergani, P., Lockless, S. W., Nairn, A. C., and Gadsby, D. C. (2005) CFTR channel opening by ATP-driven tight dimerization of its nucleotide-binding domains. Nature 433, 876-880.

54. Studier, F. W., and Moffatt, B. A. (1986) Use of bacteriophage T7 RNA polymerase to direct selective high-level expression of cloned genes. J. Mol. Biol. 189, 113-130.

55. Miroux, B., and Walker, J. E. (1996) Over-production of proteins in Escherichia coli: Mutant hosts that allow synthesis of some membrane proteins and globular proteins at high levels. J. Mol. Biol. 260, 289-298.

56. Morein, S., Henricson, D., and Rilfors, L. (1994) Separation of Inner and Outer-Membrane Vesicles from Escherichiacoli in SelfGenerating Percoll Gradients. Anal. Biochem. 216, 47-51.

57. Laemmli, U. K. (1970) Cleavage of structural proteins during the assembly of the head of bacteriophage T4. Nature 227, 680-685.

58. Schagger, H., and von Jagow, G. (1991) Blue native electrophoresis for isolation of membrane protein complexes in enzymatically active form. Anal. Biochem. 199, 223-231.

59. Wu, C. S., and Chen, G. C. (1989) Adsorption of proteins onto glass surfaces and its effect on the intensity of circular dichroism spectra. Anal. Biochem. 177, 178-182.
60. Compton, L. A., and Johnson, W. C., Jr. (1986) Analysis of protein circular dichroism spectra for secondary structure using a simple matrix multiplication. Anal. Biochem. 155, 155-167.

61. Whitmore, L., and Wallace, B. A. (2004) DICHROWEB, an online server for protein secondary structure analyses from circular dichroism spectroscopic data. Nucleic Acids Res. 32, W668-W673.

62. Sehgal, P., Mogensen, J. E., and Otzen, D. E. (2005) Using micellar mole fractions to assess membrane protein stability in mixed micelles. Biochim. Biophys. Acta 1716, 59-68.

63. Robertson, A. D., and Murphy, K. P. (1997) Protein structure and the energetics of protein stability. Chem. Rev. 97, 1251-1267.

64. Wolfram, S. (2004) The mathematica book, 5th ed., Wolfram Media, Champaign, IL.

65. Fasman, G. D. (1993) Distinguishing transmembrane helices from peripheral helices by circular dichrosim. Biotechnol. Appl. Biochem. $18,111-138$.

66. Gerald, D. (1996) Circular dichroism and the conformational analysis of biomolecules, Plenum, New York.

67. Havel, H. A. (1996) Spectroscopic methods for determining protein structure in solution, $\mathrm{VCH}$, New York.

68. Eftink, M. R. (1991) Fluorescence Techniques for Studying Protein Structure. Methods Biochem. Anal. 35, 127-205.

69. Reshetnyak, Y. K., Koshevnik, Y., and Burstein, E. A. (2001) Decomposition of protein tryptophan fluorescence spectra into lognormal components. III. Correlation between fluorescence and microenvironment parameters of individual tryptophan residues. Biophys. J. 81, 1735-1758.

70. Redfield, C. (2004) Using nuclear magnetic resonance spectroscopy to study molten globule states of proteins. Methods 34, 121-132.

71. Takagi, F., Koga, N., and Takada, S. (2003) How protein thermodynamics and folding mechanisms are altered by the chaperonin cage: Molecular simulations. Proc. Natl. Acad. Sci. U.S.A. 100, 11367-11372.

72. Voegele, R. T., Sweet, G. D., and Boos, W. (1993) Glycerol kinase of Escherichia coli is activated by interaction with the glycerol facilitator. J. Bacteriol. 175, 1087-1094.

73. Hill, W. G., Rivers, R. L., and Zeidel, M. L. (1999) Role of leaflet asymmetry in the permeability of model biological membranes to protons, solutes, and gases. J. Gen. Physiol. 114, 405-414.

74. Palanivelu, D. V., Kozono, D. E., Engel, A., Suda, K., Lustig, A., Agre, P., and Schirmer, T. (2006) Co-axial association of recombinant eye lens aquaporin-0 observed in loosely packed 3D crystals. J. Mol. Biol. 355, 605-611.

75. Kentner, D., and Sourjik, V. (2006) Spatial organization of the bacterial chemotaxis system. Curr. Opin. Microbiol. 9, 619-624.

76. Haltia, T., and Freire, E. (1995) Forces and factors that contribute to the structural stability of membrane proteins. Biochim. Biophys. Acta 1241, 295-322.

77. Haltia, T., Semo, N., Arrondo, J. L., Goni, F. M., and Freire, E. (1994) Thermodynamic and structural stability of cytochrome c oxidase from Paracoccus denitrificans. Biochemistry 33, 97319740.

78. O’Brien, E. P., Dima, R. I., Brooks, B., and Thirumalai, D. (2007) Interactions between hydrophobic and ionic solutes in aqueous guanidinium chloride and urea solutions: Lessons for protein denaturation mechanism. J. Am. Chem. Soc. 129, 7346-7353.

79. Bose, K., and Clark, A. C. (2001) Dimeric procaspase-3 unfolds via a four-state equilibrium process. Biochemistry 40, 14236-14242.

80. Luo, W. B., Yao, X. L., and Hong, M. (2005) Large structure rearrangement of colicin la channel domain after membrane binding from 2D C-13 spin diffusion NMR. J. Am. Chem. Soc. 127, 64026408.

81. Jensen, M. O., Tajkhorshid, E., and Schulten, K. (2001) The mechanism of glycerol conduction in aquaglyceroporins. Structure 9, 1083-1093.

82. deGroot, B. L., and Grubmuller, H. (2001) Water permeation across biological membranes: Mechanism and dynamics of aquaporin-1 and GlpF. Science 294, 2353-2357.

83. Salzmann, M., Pervushin, K., Wider, G., Senn, H., and Wuthrich, K. (1998) TROSY in triple-resonance experiments: New perspectives for sequential NMR assignment of large proteins. Proc. Natl. Acad. Sci. U.S.A. 95, 13585-13590.

84. Sanders, C. R., and Sonnichsen, F. (2006) Solution NMR of membrane proteins: Practice and challenges. Magn. Reson. Chem. $44, \mathrm{~S} 24-\mathrm{S} 40$ 